\title{
Correction to: On the spectral norms of $r$-circulant matrices with the bi-periodic Fibonacci and Lucas numbers
}

\section{Cahit Köme and Yasin Yazlik}

\section{"Correspondence:}

yyazlik@nevsehir.edu.tr

Department of Mathematics,

Nevşehir Hacı Bektaş Veli University, Nevşehir, Turkey

\section{Correction}

In the publication of this article [1], there are a few errors.

(1) Page 4, line 4:

The statement $\frac{1}{(a b)^{m+1}}\left[\alpha^{2 m+1}+\beta^{2 m+1}-(-1)^{m}\right]-2$ should instead read: $\frac{1}{(a b)^{m+1}}\left[\alpha^{2 m+1}+\beta^{2 m+1}\right]+(-1)^{m}-2$.

(2) Page 4, line 6:

The statement $\left(\frac{1}{a}\right) l_{m} l_{m+1}=\frac{1}{(a b)^{m+1}}\left[\alpha^{2 m+1}+\beta^{2 m+1}-(-1)^{m}\right]$ should instead read: $\left(\frac{1}{a}\right) l_{m} l_{m+1}=\frac{1}{(a b)^{m+1}}\left[\alpha^{2 m+1}+\beta^{2 m+1}\right]+(-1)^{m}$.

(3) Page 8, Equation (16):

The matrix $F$ should instead read:

$$
F=\left[\begin{array}{ccccc}
1 & 1 & 1 & \ldots & 1 \\
r\left(\frac{b}{a}\right)^{\frac{\xi(n-1)}{2}} l_{n-1} & 1 & 1 & \ldots & 1 \\
r\left(\frac{b}{a}\right)^{\frac{\xi(n-2)}{2}} l_{n-2} & r\left(\frac{b}{a}\right)^{\frac{\xi(n-1)}{2}} l_{n-1} & 1 & \ldots & 1 \\
\vdots & \vdots & \vdots & \ddots & \vdots \\
r\left(\frac{b}{a}\right)^{\frac{\xi(1)}{2}} l_{1} & r\left(\frac{b}{a}\right)^{\frac{\xi(2)}{2}} l_{2} & r\left(\frac{b}{a}\right)^{\frac{\xi(3)}{2}} l_{3} & \ldots & 1
\end{array}\right] .
$$

(4) Page 8, line 15: The equation $r_{1}(F)$ should instead read:

$$
r_{1}(F)=\max _{1 \leq i \leq n} \sqrt{\sum_{j=1}^{n}\left|f_{i j}\right|^{2}}=\sqrt{1+|r|^{2} \sum_{k=1}^{n-1}\left(\frac{b}{a}\right)^{\xi(k)}} l_{k}^{2}=\sqrt{1+|r|^{2}\left(\frac{l_{n} l_{n-1}}{a}-2\right)} .
$$

(5) Page 9, lines 2 and 4, page 10, line 11 and Theorem 2.3 on page 7:

The statement $|r|\left(\frac{l_{n} l_{n-1}}{a}+2\right)$ should instead read:

$$
\sqrt{\frac{l_{n} l_{n-1}}{a}+2} \sqrt{1+|r|^{2}\left(\frac{l_{n} l_{n-1}}{a}-2\right)} \text {. }
$$

(6) Page 10, line 20:

The statement $|r|^{2} \frac{q_{n} q_{n-1}}{a}\left(\frac{l_{n} l_{n-1}}{a}+2\right) l$ should instead read:

$$
|r| \frac{q_{n} q_{n-1}}{a} \sqrt{\frac{l_{n} l_{n-1}}{a}+2} \sqrt{1+|r|^{2}\left(\frac{l_{n} l_{n-1}}{a}-2\right)} .
$$

(c) The Author(s) 2018. This article is distributed under the terms of the Creative Commons Attribution 4.0 International License (http://creativecommons.org/licenses/by/4.0/), which permits unrestricted use, distribution, and reproduction in any medium, provided you give appropriate credit to the original author(s) and the source, provide a link to the Creative Commons license, and indicate if changes were made. 
This has now been included in this erratum.

\section{Acknowledgements}

The authors are grateful to the anonymous referees who have contributed to improve the quality of the paper. The authors declare that they have not received any financial support to do this research.

\section{Competing interests}

The authors declare that there are no competing interests with any individual or institution.

\section{Authors' contributions}

All authors contributed equally to the writing of this paper. All authors read and approved the final manuscript.

\section{Publisher's Note}

Springer Nature remains neutral with regard to jurisdictional claims in published maps and institutional affiliations.

Received: 6 January 2018 Accepted: 6 January 2018 Published online: 22 February 2018

\section{References}

1. Köme, C., Yazlik, Y.: On the spectral norms of $r$-circulant matrices with the biperiodic Fibonacci and Lucas numbers. J. Inequal. Appl. 2017(1), 192 (2017). https://doi.org/10.1186/s13660-017-1466-0 